ally required. Sorting and microfilming is likely to be too time-consuming to be profitable.

It it is impossible for hospitals to preserve case notes for a useful period of time could not some central storage depot be instituted in each region or area, where old medical records would be available to any hospital?

It is a depressing thought that as fast as one is making careful and detailed clinical notes during one year, a "medical records destruction officer" is steadily tearing them up a few years later.-I am, etc.,

ERIC C. O. JEWESBURY

London $\mathbf{W} .1$

\section{Preclinical Salaries}

SIR,-With reference to Professor G. R. Kelman's letter (28 August, p. 537) querying my statement that there is a $5 \%$ differential between the preclinical and clinical salaries, I was in error. He is correct, and I am glad he has given some concrete examples of the great disparity between clinical and preclinical salaries. I must confess that my $5 \%$ differential was quoted from memory of official B.M.A. policy, which was declared in their submission to the National Board for Prices and Incomes (1969), and which argued that medically qualified teachers should receive at least $90 \%$ of that received by their clinical colleagues.

I would point out that at the recent A.R.M. at Leicester the motion that ". . . all medical graduates employed in university preclinical and clinical departments should be on the same salary scale" was carried (Supplement, 31 July, p. 76).

It would seem from the evidence which has already been given in your correspondence columns that the differential is greater than the declared official policy of the B.M.A. This makes me more convinced than ever that a policy of no differentials between the salaries of clinical and preclinical disciplines should be adopted by the B.M.A., the Universities, and the Association of University Teachers in order to halt the deterioration in the present position and to aid recruitment in the future.-I am, etc.,

Pathology Unit,

Royal Free Hospital,

KENNETH R. HIIL

London W.C.1

\section{Hospital Staff Appointments}

SIR,-It is high time that the correspondence on this subject was brought back to my original thesis, judging by your latest correspondents (11 September, p. 638) who, along with others who have equally sought to misuse its purpose in order to ventilate their grievances against appointing committees, have forgotten (or never realized) the simple point of my inaugural letter (22 May, p. 470). In effect, this stated that having finally decided to accept an appointment, a candidate must honour that acceptancevoluntarily, or otherwise.

While I naturally sympathize with sufferers from unpleasant experiences while seeking hospital staff appointments (and I myself have been far from immune from such ex- periences) I submit that the correction of such malpractice must be the subject of an entirely different investigation.-I am, etc.,

East Glamorgan General Hospital,
Glam

J. DE SWIET

\section{Sauce, Spices, and the Kidney}

SIR,-I agree with your leading article (3 July, p. 6) that the number of people who take sufficient Worcestershire sauce to cause kidney damage must be small. But, when I reported the association of excess sauce and kidney stones ${ }^{1}$ or general renal failure; ${ }^{2}$ I had in mind the potential implications in people who habitually take similar spices in large amounts. The countries with very high incidence of renal tract stones include parts of India and Mexico, ${ }^{3}$ where curry and other hot spices are very popular. If these condiments can be shown to be contributing to the kidney troubles, the number of people potentially involved is very great.

I have found that most visitors from India, when offered the suggestion that curry could be a factor in their country's renal problems, react as if a national institution has been maligned. It was therefore very gratifying to note the observation by Mr. G. Holmes (24 July, p. 252) that kidney stones are very common in Fijian Indians, and scarcely ever occur in Fijians, and that the difference could be due to "curry kidney." - I am, etc.,

\section{Princess Alexandra Hospital,}

K. J. MURPHY

Woolloongabba, Brisbane,
Queensland, Australia

1 Murphy, K. J., Lancet, 1967, 2, 401. 1, 1119 .

Straffon, R. A., and Higgins, C. C., in Urology,
ed. M. F. Campbell and J. H. Harrison, 3rd edn. W. B. Saunders Co., London, 1970, Vol. I, p. 688 .

\section{"Clinical" and "Administrative" Pharmacists}

SIR,-It is encouraging to read letters expressing apprehension at the currently held idea that the normal promotional ladder of any profession rises naturally beyond the technical field to that of administration and management.

The Health Service is concerned with the patient as an individual and the closer one works to the patient the more exacting, specialized, and demanding the work becomes. The medical profession realized this and accepted the Cogwheel system ${ }^{1}$ as a method of self administration. At the same time it is normal to achieve professional eminence as a doctor without having of necessity to become an administrator.

Your correspondents suggest that there is a defect in the Salmon report inasmuch as a nurse can only rise up the promotional ladder by "defecting" to the administrative field. As a hospital pharmacist may I suggest that precisely the same "blind spot" appears in the Noel Hall report for the reorganization of hospital pharmacy. ${ }^{2}$ At the head of the financial scale, and possessing executive power, is the regional pharmacist. Next below him is the area pharmacist controlling some 6,000 beds-probably some three or four existing groups. He is to have power of deployment of the area pharma- ceutical forces, and his will be an administrative job.

The individual pharmacist working in a hospital may not have the authority or professional freedom which would place him on a professional level with the senior medical and nursing officers in his own hospital. Nor can he rise to any career salary level. If a "clinical" pharmacist wishes to make a promotional career he will have to desert working pharmacy for administration following the latest god of managerial efficiency.

Since the publication of these various reports there has developed some feeling that undue emphasis has been placed on the preeminence of managerial and administrative functions in professions which are basically concerned with scientific technicalities, and it is to be hoped that notice will be taken of these views to redirect the balance of change. -I am, etc.

J. FOGG

Royal Alexandra Hospital,

Rhyl

1 Organization of Medical Work in Hospitals. London, H.M.S.O., 1967.

Department of Health and Social Security. Scottish Home and Health Department. Welsh Office. Report of the Working Party on the Hospital
Pharmaceutical Service. London, H.M.S.O., 1970.

\section{Cremation Regulations}

SIR,-I should like to preface what follows by the emphatic statement that this is not intended as a criticism of Her Majesty's coroners, who, in my experience, perform a difficult task with skill and tact.

I am a referee of the Norwich Crematorium Limited, and in this capacity it is one of my duties to countersign Form F of the Application for Cremation form in cases which have been reported to the coroner and a postmortem has been held because the general practitioner or hospital doctor has been unable to sign the death certificate. I am provided with certain sections of the Application for Cremation form which are Form A (which is an application for cremation), the coroner's Certificate E, in which the coroner expresses his satisfaction that cremation may go forward, and Form F, which I am required to sign as the final authority to cremate. In Form F, it states that "I have satisfied myself that all the requirements of the Cremation Acts, 1902 and 1952, and of the Regulations made in pursuance of those Acts, have been complied with, that the cause of death has been definitely ascertained, and that there exists no reason for any further inquiry or examination."

Obviously I do not doubt the coroner's word, but I am expected to sign this form without having any knowledge of the cause of death. This has led me to correspond with the Home Office, which has been most helpful in answering my queries, and from which I gather that the changes introduced by the Cremation Regulations of 1965 were discussed with the B.M.A., the Home Office, and the Coroner's Society of England and Wales Committee. May I quote two relevant points from the letter written to me by a Home Office official?

"The purpose of Regulation 1 of these new Regulations was to remove the prohibition of Cremation, which formerly existed, in those cases in which an inquest had been opened, but not completed, although all the 
necessary examinations of the body had been made. Having regard to the fact that Form $\mathrm{E}$ would sometimes be issued before a formal verdict had been returned the cause of death was omitted from the revised Form E to avoid any difficulties which might otherwise arise."

"We have no doubt that the intention of the Regulations was to enable the referee to rely on the coroner's enquiry and it would seem that they have normally been interpreted that way. It seems to us open to a medical referee to satisfy himself that the cause of death has been ascertained if the death has been reported to the coroner and the latter has issued Form E. On this interpretation of the Regulations it is not the cause of death established by a coroner in a particular case but the fact that the coroner has issued Form $E$ on which the medical referee relies in satisfying himself that the cause of death has been adequately ascertained ....."

Furthermore, the letter from the Home Office made it clear that a revision of the Regulations may be required if my request to know the cause of death is to be met, and such revision may have to await the report of the Brodrick committee. I hope that the members of the Brodrick committee will appreciate that though the coroner's accurate assessment of a case is in no way challenged, sureiy the referee should have the right before signing Form $F$, to be aware of the cause of death. It seems to me that common courtesy as well as common sense demands this.-I am, etc.,

Bergh Apton,

Hugh C. MaIngaY Norfolk

\section{Periodic Haemorrhages in Haemophilia A}

SIR,-Spontaneous haemorrhages in patients with haemophilia $A$ are known to be frequently cyclic. ${ }^{1}$ Still, periodic haemorrhages are not mentioned in published retrospective $^{2-4}$ or prospective ${ }^{5}$ studies of patients with this disorder. I have attempted to detect a possible seasonal recurrence of bleeding bouts by a retrospective examination of hospital admissions and of individual case histories of patients with haemophilia $\mathbf{A}$.

The survey of 45 patients with haemophilia A diagnosed between 1950 and 1970 in Tel-Hashomer and Hadassah hospitals in Israel showed an increased incidence of hospital admissions during July-August and December-January (Fig.). This finding did not support the impression reported by most patients and some clinicians, that patients with haemophilia bleed mainly during the transitional seasons (March-April, September-October). However, the data were compatible with a somewhat higher incidence of haemorrhages during summer and winter, and therefore several individual case histories were further studied.

The haematology service of the Hadassah University Hospital serves 14 patients with haemophilia $A$, of whom five have been followed for 13 to 28 years. Pertinent data on these five patients are given in the Table. In four of them more than $70 \%$ of the bleeding events, which had required hospital admission and/or replacement therapy, were confined to less than six of the months of the year: in patients $A, D$, and $E$ the haemorrhages recurred mainly in winter, winter and summer, and summer respectively; in patient $C$ they occurred mainly during the transitional seasons. The bleeding bouts in patient $B$ as well as those in six other patients who had been followed for shorter periods did not appear to conform to any seasonal or other rhythmic pattern.

The bleeding episodes in some adult patients with haemophilia seem, therefore, to show an unexplained tendency to seasonal recurrence, even though there are considerable variations in the pattern of this periodicity among individual cases. It should be noted that the observations presented here are based on recorded bleeding episodes only, and probably exclude a considerable number of minor haemorrhagic events. If confirmed by prospective studies on a larger number of patients this periodicity may suggest that in some patients with haemo- philia preventive therapy could be feasible at a reasonable cost by its confinement to the "high risk" months.-I am, etc.

Haematology Service,

J. BenBassat

Jerusalem,

Israel

1 Wintrobe, M. M., Clinical Haematology, 6th edn.,

Ramgren, O., Acta Medica Scandinavica, 1962, 171, Suppl. 379, p. 111.

wilkinson, J. F.; Nour-Eldin, F., Israëls, M. C. G., and Barret, K. E., Lancet, 1961, 2,

Ikkala, E., Scandinavian foumal of Laboratory and Clinical Investigation, 1960, 12, Suppl. 46. Girwood, R. H., and Darg, A., British Medical foumal, 1966, 2, 1624

\section{Name Badges for Technical and Ancillary Stafi}

SIR,-For some time now it has been the practice in many hospitals for medical staff, particularly junior medical staff, to wear name badges, which also indicate the department in which the doctor is working. I personally support this as being helpful to patients and making for better communications, particularly with regard to the rapid turnover of doctors between different posts at more junior levels. There has been some discussion as to whether the system should be extended to include technical staff and eventually, presumably, all ancillary staff.

Might I venture to suggest that before the Department of Health and Social Security makes any recommendation or policy on this the views of the patients and others concerned should be sought? After all, it is primarily for the benefit of patients, who may be confused by the multiplicity of white-coated figures attending them, that the system is in use.-I am, etc.,

Notley Hospital,

A. Platten Braintree, Essex

\section{Air Embolism during Faemodialysis}

SIR,-Dr. M. K. Ward and others (10 July, p. 74) report the occurrence of clinically important air embolism in about 1 in 2,000 haemodialyses. They do not state the number of dialyses in which an arteriovenous fistula, as opposed to an arteriovenous shunt, was being used. This method of access to the blood stream, with its great advantages to the patient, is becoming common, but its use introduces another possible portal of entry for air embolism which they have not encountered.

In a long experience, dating back to 1959 , of pumped and pumpless dialysis circuits, we have never encountered clinical air embolism from any of the sites of air entry described by Dr. Ward and his colleagues. However, we have had one non-fatal episode of air embolism severe enough to cause cyanosis hypotension, and transient loss of consciousness similar to their Case 5. This occurred when the arterial needle came out of the fistula and the pump pumped air instead of blood into the circuit. This occurred during the momentary absence of the dialysis nurse towards the end of our first 500 fistule haemodialyses.

This experience underlined for us the need 